\title{
Avaliação Institucional: mapeamento e análise das concepções de qualidade e melhoria nas produções da revista Estudos em Avaliação Educacional (1990-2013)
}

\author{
Pamela Cristina Botiglieri \\ Regilson Maciel Borges \\ José Carlos Rothen
}

Resumo: O artigo apresenta um mapeamento e análise da produção sobre avaliação institucional publicada na revista Estudos em Avaliação Educacional da Fundação Carlos Chagas (FCC), no período de 1990 a 2013. Na pesquisa objetivou-se analisar como é tratada a relação entre qualidade e melhoria quando se discute a avaliação institucional. A fim de se atingirem os objetivos propostos realizou-se uma pesquisa bibliográfica no site da revista disponível no portal da FCC. No levantamento foram selecionados um total de 23 artigos de um total de 42 trabalhos encontrados sobre a temática analisada. Os resultados mostram a predominância de artigos que tratam da avaliação institucional com foco na educação superior. Outra constatação é a predominância de artigos provenientes de instituições localizadas na região sudeste do país, com destaque para a Pontifícia Universidade Católica de São Paulo e a FCC. Dos 27 autores que tiveram suas produções selecionadas, três autores publicaram mais de um artigo. Observa-se ainda que o interesse pela temática analisada se deu após o ano 2000, quando se concentra a maioria da produção selecionada. Sobre as concepções de qualidade e melhoria, os autores as associam ao cumprimento da função social da instituição. Nessa acepção a avaliação institucional aparece como um meio para ter um diagnóstico institucional, com objetivo de fornecer subsídios para que se pense ações geradoras de melhoria.

Palavras-chave: Avaliação institucional. Estudos em avaliação educacional. Qualidade e melhoria.

\section{Institutional Assessment: mapping and analysis of quality improvement}

and conceptions in the magazine productions Studies in Educational Evaluation (1990-2013)

Abstract: The article presents a mapping and analysis of the literature on institutional evaluation published in the journal Studies in Educational Evaluation of the Carlos Chagas Foundation (FCC) from 1990 to 2013. The survey aimed to analyze how it is treated the relationship between quality improvement and when discussing the institutional assessment. In order to achieve the proposed objectives, we carried out a literature review on the magazine's Web site available on the FCC website. In the survey were selected a total of 23 articles of a total of 42 works found from within the analysis. The results show a predominance of articles dealing with institutional evaluation focusing on higher education. Another finding is the predominance of articles from institutions located in the southeastern region of the country, especially the Pontifical Catholic University of São Paulo and the FCC. Of the 27 authors who had their productions selected three authors published more than one item. It is also observed that the interest in the analyzed issue occurred after 2000, when it concentrates most of the selected production. On the concepts of quality and improvement, the authors associate with the fulfillment of the social function of the institution. In this sense the institutional assessment appears as a means to have an institutional diagnosis, in order to provide subsidies to think that generating actions for improvement.

Key words: Institutional assessment. Studies in educational evaluation. Quality and improvement. 


\section{Introdução}

Este trabalho objetivou analisar a produção sobre Avaliação Institucional publicada na revista Estudos em Avaliação Educacional da Fundação Carlos Chagas (FCC), no período de 1990 a 2013. Na pesquisa buscamos verificar como os autores que publicam na revista compreendem a relação entre qualidade e melhoria quando se trata da temática da avaliação institucional.

Partimos do pressuposto de que a avaliação deve ter caráter eminentemente pedagógico, implicando diretamente na melhoria da qualidade da educação. Para isso, ela deve ser utilizada para oferecer instrumentos que aponte a realidade institucional, identifiquem-se problemas e/ou situações que precisam ser alteradas e se pense como melhorá-los. Sabendo, então, das possibilidades de relação entre avaliação institucional e melhoria na qualidade da educação, considera-se relevante compreender de que maneira é tratada esta questão por um dos veículos de comunicação científica sobre avaliação reconhecido pela área da educação.

A escolha da revista Estudos em Avaliação Educacional enquanto objeto deste estudo considerou a sua relevância para a área educacional, especificamente seu destaque na área das pesquisas em avaliação educacional, conforme apontam alguns estudos que analisaram a produção da revista no tocante à temática da avaliação educacional no Brasil (CANDAU; OSWALD, 1995; BARRETTO; PINTO, 2001; SAMESHIMA, 2004). Nestes trabalhos a revista aparece com grande concentração de textos diante de outros periódicos da área, o que caracteriza a pertinência e destaque de sua produção para a temática pesquisada.

No que diz respeito ao interesse pelo foco da Avaliação Institucional, convém ressaltar que este está sendo entendido com um dos níveis integrantes da Avaliação Educacional, tal como postulam Freitas et al. (2009). Para os autores a avaliação educacional comporta três níveis integrados: Avaliação em sala de aula (sob responsabilidade do professor), avaliação em larga escala (em redes de ensino) e a avaliação institucional, sendo esta última aquela realizada em cada escola, por seu coletivo, que engloba o todo da instituição escolar.

A respeito dessa dimensão do todo escolar, Dias Sobrinho (1994) salienta que a avaliação institucional é um processo que requer a adesão coletiva, e deve, segundo o autor, ser:

[...] sistemática e sistematizadora. Deve referir-se metódica e coerentemente ao conjunto, organizada no tempo e articulada no tecido institucional. Mas também dever ser uma prática que contribua para dar consciência aos sentidos da instituição, que organize as múltiplas formas de se compreender a universidade e a ajude a desenvolver em conformidade a seus princípios e programas (DIAS SOBRINHO, 1994, p. 122).

Assim, para além de serem práticas pontuais e fragmentadas, “[...] a avaliação institucional consiste num empreendimento sistemático que busca compreensão global da Universi- 
Avaliação Institucional: mapeamento e análise das concepções de qualidade e melhoria nas produções da revista Estudos em Avaliação Educacional (1990-2013)

dade, pelo reconhecimento e pela integração de suas diversas dimensões [...]" (BALZAN; DIAS SOBRINHO, 1995, p. 9), que possibilite “[...] repensar o significado da participação dos diferentes atores na vida e no destino das escolas", o que implica nesta proposta a recuperação da "dimensão coletiva do projeto político-pedagógico", ou seja, "refletir sobre suas potencialidades, vulnerabilidades e repercussões em nível de sala de aula, junto aos estudantes" (FREITAS et al., 2009, p. 35).

A fim de se atingirem os objetivos do estudo, realizamos uma pesquisa bibliográfica em bases da revista disponíveis online no site da Fundação Carlos Chagas. A pertinência da pesquisa bibliográfica, segundo Marconi e Lakatos (2003, p. 183), está na possibilidade de exploração de novas áreas, propiciando "o exame de um tema sob novo enfoque ou abordagem, chegando a conclusões inovadoras".

\begin{abstract}
A pesquisa bibliográfica é um apanhado geral sobre os principais trabalhos já realizados, revestidos de importância, por serem capazes de fornecer dados atuais e relevantes relacionados com o tema. O estudo da literatura pertinente pode ajudar a planificação do trabalho, evitar publicações e certos erros, e representa uma fonte indispensável de informações, podendo até orientar as indagações (MARCONI; LAKATOS, 2003, p. 158).
\end{abstract}

$\mathrm{O}$ estudo foi desenvolvido em duas fases. Na primeira foi realizado um levantamento dos artigos do periódico estudado, tendo como base o banco de dados da própria Fundação Carlos Chagas (disponível em http://www.fcc.org.br). Nesta fase foram considerados como descritores de busca as palavras-chave "avaliação institucional", "avaliação da escola" e "avaliação escolar". Os descritores foram pesquisados no campo "assunto" e também no campo “título". Foram encontrados um total de 42 artigos, destes, 23 tratavam da temática pesquisada. Após esta seleção, os artigos foram organizados em tabelas Microsoft Excell segundo “ano", "autor", “dados do autor" (formação e vínculo institucional), "título do artigo", e "palavras-chave" utilizadas pelos autores dos textos. A realização desta fase possibilitou o cruzamento de dados quantitativos que indicaram os anos em que se concentram as publicações, os autores que mais publicaram, a origem institucional (Universidades, Centros de Pesquisa, e outros) e regional (Norte, Nordeste, Sul, Sudeste, Centro-Oeste, Sul) dos artigos e sua distribuição por níveis de ensino (básico e superior).

$\mathrm{Na}$ segunda fase da pesquisa, foi feita a leitura integral dos artigos selecionados, com o preenchimento de fichas de leitura que foram elaboradas para responder as seguintes questões: "Qual é a concepção de qualidade e de melhoria presente nos artigos?", "Existe relação entre avaliação institucional e melhoria na qualidade? Se sim, de que maneira?". Com isso buscou-se analisar as semelhanças, diferenças e divergências presentes nos artigos, em relação aos temas citados, na tentativa de se obter melhor parâmetro e compreensão das concepções 
presentes nos artigos da revista sobre os mesmos. Esta segunda fase permitiu o cotejamento qualitativo da produção, bem como a construção de um panorama teórico de sua produção a respeito da temática pesquisada.

O presente artigo está organizado em três seções. Na primeira se caracteriza a revista e sua relevância para os estudos em avaliação educacional. Na segunda é apresentado o mapeamento da produção da revista. Na terceira analisam-se as concepções de qualidade, melhoria e a possibilidade de relação entre avaliação educacional e melhoria presente nos artigos analisados.

\section{Caracterização da revista Estudos em Avaliação Educacional}

Criado em 1990 e editado pela Fundação Carlos Chagas (FCC) como continuidade da revista Educação e Seleção, que foi publicado de 1980 a 1989, o periódico Estudos em Avaliação Educacional tem como objetivo publicar trabalhos direta ou indiretamente relacionados com a questão da avaliação educacional, apresentados sob a forma de relatos de pesquisas, ensaios teóricos, revisões críticas, artigos e resenhas.

Estudos em Avaliação Educacional tem publicação quadrimestral, com tiragem de 400 exemplares e encontra-se disponível para consulta online no site da FCC. A revista congrega em seu comitê editorial pesquisadores vinculados à própria FCC, sob coordenação de Gláucia Torres Franco Novaes, Adriana Bauer, Bernardete A. Gatti, Clarilza Prado de Sousa, Glória, Maria Santos Pereira Lima, Marialva Rossi Tavares, Nelson A. Simão Gimenes e Vandré Gomes da Silva. Seu conselho editorial é formado por renomados pesquisadores de diferentes instituições de pesquisas brasileiras, dentre os quais se encontram: Dalton Francisco de Andrade (UFSC), Fernando Lang da Silveira (UFRGS), Heraldo Marelim Vianna (FCC, in memoriam), José Francisco Soares (UFMG), Lina Kátia Mesquita de Oliveira (UFJF), Luzia Marta Bellini (UEM), Maria Inês G. de Sá Pestana (INEP), Naura Syria Carapeto Ferreira (UTP), Nícia Maria Bessa (PUC-RJ), Nigel Pelham de Leighton Brooke (UFMG), Robert Vehine (UFBA), Sandra Zakia Sousa (USP), Sérgio Vasconcellos de Luna (PUC-SP) e Yara Lúcia Esposito (FCC).

De acordo com a avaliação de periódicos realizada pela Coordenação de Aperfeiçoamento de Pessoal de Nível Superior (QUALIS/CAPES ${ }^{1}$ ), em seu Sistema WebQualis, a revis-

\footnotetext{
${ }^{1}$ De acordo com informações do site da Capes o Qualis é o conjunto de procedimentos utilizados pela Capes para estratificação da qualidade da produção intelectual dos programas de pós-graduação, aferindo a qualidade dos artigos e de outros tipos de produção, a partir da análise da qualidade dos veículos de divulgação, ou seja, periódicos científicos e anais de eventos.
} 
Avaliação Institucional: mapeamento e análise das concepções de qualidade e melhoria nas produções da revista Estudos em Avaliação Educacional (1990-2013)

ta aparece com um estrato "A2" na área da Educação². Esse estrato indica que o periódico possui uma projeção internacional, enquadrando-se nos itens avaliados para essa finalidade.

A partir disso, considera-se que esse periódico se constitui em grande relevância para a área dos estudos em avaliação, conforme apontam os estudos realizadas por Candau e Oswald (1995), Barretto e Pinto (2001) e Sameshima (2004) nas quais a revista aparece com grande destaque pela concentração de artigos que discutem a temática da avaliação educacional no Brasil.

Na pesquisa de Candau e Oswald (1995), que analisou 124 artigos sobre avaliação educacional, distribuídos em onze periódicos da área da educação, do período de 1980 a 1992, a produção se concentra em três revistas: Tecnologia Educacional, com 25 artigos; Educação e Seleção, com 24 artigos; e Estudos em Avaliação Educacional, com 21 artigos. Essa constatação do acúmulo de produções sobre a temática da avaliação em dois periódicos editados pela FCC - Educação e Seleção e Estudos em Avaliação Educacional - faz com que as autoras reconheçam que a Fundação "constitui o principal centro de produção do conhecimento na área" (CANDAU; OSWALD, 1995, p. 36).

No estudo de Barretto e Pinto (2001), ao analisarem 218 artigos de nove periódicos da área, do período de 1990 a 1998, com foco na avaliação na educação básica, as autoras constatam que a produção também se concentra em três revistas, são elas: Estudos em Avaliação Educacional, com 92 artigos; Ensaio: Avaliação e Políticas Públicas em Educação, com 49 artigos; e Cadernos de Pesquisa, com 27 artigos.

Também Sameshima (2004), ao estudar 72 artigos sobre avaliação institucional publicados em treze periódicos nacionais da área da educação, no período de 1990 a 2002, evidencia grande concentração de artigos em três periódicos: Avaliação: Revista da Avaliação da Educação Superior, responsável por $68 \%$ da produção sobre o tema, seguida pela revista Ensaio: Avaliação e Políticas Públicas em Educação, com 16\% e pela revista Estudos em Avaliação Educacional, com $10 \%$ da produção analisada.

Além disso, de acordo com Gonçalves Filho (2003, p. 51), dentro 80 periódicos científicos brasileiros de educação avaliados em cooperação pela Associação Nacional de PósGraduação e Pesquisa em Educação (ANPED), Associação Brasileira de Tecnologia Educacional (ABT), Instituto Nacional de Estudos e Pesquisas Educacionais Anísio Teixeira (INEP) e Coordenação de Aperfeiçoamento de Pessoal de Nível Superior (CAPES) nos anos 2001/02,

\footnotetext{
${ }^{2}$ No Qualis os periódicos são enquadrados em sete estratos indicativos da qualidade, sendo o A1, o mais elevado; A2; B1; B2; B3; B4; B5; e C, com peso zero.
} 
dois são os periódicos que estão voltados especificamente para o campo da avaliação, trata-se da Revista Avaliação da Rede de Avaliação Institucional da Educação Superior (RAIES) e da Revista Estudos em Avaliação Educacional da FCC.

Em recente estudo Poltronieri (2011), focada na avaliação da aprendizagem na educação básica, analisa a produção científica divulgada na revista Estudos em Avaliação Educacional no período de 1990 a 2010. A partir da análise de 107 artigos produzidos ao longo do período pesquisado, a autora conclui que a revista possui um caráter mais técnico do que político no trato da avaliação, principalmente por ser uma revista "que se distancia de discussões teóricas de cunho político-ideológico e que privilegia autores que tratam da avaliação no âmbito do fazer no cotidiano educacional e na execução das políticas públicas” (p.132).

Em outro artigo, aprofundando os resultados da pesquisa desenvolvida por Poltronieri (2011), Poltronieri e Calderón (2012) apontam que a revista Estudos em Avaliação Educacional, juntamente com a revista Ensaio: Avaliação e Políticas Públicas em Educação, editada pela Fundação Cesgranrio, se constituem no Brasil como referências fundamentais à disseminação de produções científicas acerca do tema específico da área de avaliação da educação básica. De certo modo, os autores incluem no grupo de revistas que discutem a temática da avaliação educacional, a revista Ensaio, até então não creditada na devida classificação, conforme mencionado anteriormente por Gonçalves Filho (2003). Com isso os autores sinalizam para uma linha de publicações que priorizam "o campo da operacionalização das políticas públicas, do aprimoramento, do fazer, do cotidiano, e da dimensão técnica da avaliação" (POLTRONIERI; CALDERÓN, 2012, p. 101).

Com essa breve exposição é possível notar que a revista Estudos em Avaliação Educacional, tem sido objeto de estudo de pesquisadores interessados nos diferentes enfoques de sua produção, que se concentram das temáticas da avaliação institucional (SAMESHIMA, 2004) à avaliação da aprendizagem (POLTRONIERI, 2011), englobando-se os níveis de ensino básico (CANDAU; OSWALD, 1995; BARRETTO; PINTO, 2001), superior (SAMESHIMA, 2004) e os dois níveis concomitantes (POLTRONIERI, 2012). Desses estudos é notório o reconhecimento das contribuições da revista em questão para as discussões do campo da avaliação brasileira. 


\section{Mapeamento da produção sobre Avaliação Institucional publicada na revista Estudos em Avaliação Educacional}

A partir do levantamento realizado por meio dos descritores "avaliação institucional", “avaliação da escola" e "avaliação escolar”, foram selecionados 23 artigos que demonstravam ter relação com o tema escolhido, conforme Tabela 1.

\section{Tabela 1 - Distribuição dos artigos por ano de publicação}

\begin{tabular}{rrr}
\hline ANO & QUANTIDADE DE ARTIGOS & PORCENTAGEM \\
\hline $\mathbf{1 9 9 0}$ & 3 & $13.04 \%$ \\
\hline $\mathbf{1 9 9 4}$ & 1 & $4.34 \%$ \\
\hline $\mathbf{1 9 9 5}$ & 1 & $4.34 \%$ \\
\hline $\mathbf{2 0 0 0}$ & 2 & $8.69 \%$ \\
\hline $\mathbf{2 0 0 4}$ & 1 & $4.34 \%$ \\
\hline $\mathbf{2 0 0 6}$ & 2 & $8.69 \%$ \\
\hline $\mathbf{2 0 0 7}$ & 1 & $4.34 \%$ \\
\hline $\mathbf{2 0 0 8}$ & 2 & $8.69 \%$ \\
\hline $\mathbf{2 0 1 0}$ & 4 & $17.39 \%$ \\
\hline $\mathbf{2 0 1 1}$ & 1 & $4.34 \%$ \\
\hline $\mathbf{2 0 1 2}$ & 4 & $17.39 \%$ \\
\hline $\mathbf{2 0 1 3}$ & 1 & $4.34 \%$ \\
\hline Total geral & 23 & $100 \%$ \\
\hline
\end{tabular}

Fonte: os autores (2014)

Nota-se, conforme demonstra Tabela 1, maior concentração de artigos que tratam do tema a partir dos anos 2000, já que se apresentam apenas cinco artigos na década de noventa, sendo três em 1990, um em 1994 e um em 1995. No ano de 2010 foram publicados quatro artigos a respeito do tema, e quatro em 2012. Os anos de 2000, 2006 e 2008 tiveram dois artigos publicados, e em 2004, 2007, 2011 e 2013 houve um artigo por ano. Já os anos 2001, 2002, 2003, 2005 e 2009 não tiveram nenhum artigo sobre a temática. Isso demonstra que, apesar de os anos de 1990 serem considerado como "a década da avaliação" no Brasil (DIAS SOBRINHO, 2003), a temática pesquisada sobre avaliação institucional só veio a receber maior atenção na revista a partir da década seguinte, anos 2000.

A respeito dos autores dos artigos encontrados, nota-se ser um conjunto bastante diversificado, tanto no que se refere a sua origem institucional quanto aos interesses de pesqui- 
sa, conforme apresentado na Tabela 2. Foram encontrado um total de 27 autores, sendo que apenas três tiveram autoria em mais de um artigo. Ressalta-se que nesta tabela o número de autores ultrapassa o número de artigos selecionados devido ao fato de que alguns artigos possuem mais de um autor.

Tabela 2 - Distribuição dos artigos por autores dos trabalhos

\begin{tabular}{|c|c|c|}
\hline AUTOR & QUANTIDADE DE ARTIGOS & PORCENTAGEM \\
\hline Clarilza Prado de Sousa & 3 & $13.04 \%$ \\
\hline Bernardete A. Gatti & 2 & $8.69 \%$ \\
\hline Zacarias Gama & 2 & $8.69 \%$ \\
\hline Bernardo Kipnis & 1 & $4.34 \%$ \\
\hline Marcos T. Masetto & 1 & $4.34 \%$ \\
\hline Ana Maria Saul & 1 & $4.34 \%$ \\
\hline Antonio Amorim & 1 & $4.34 \%$ \\
\hline Sandra M. Zákia Lian Sousa & 1 & $4.34 \%$ \\
\hline Heraldo Marelim Vianna & 1 & $4.34 \%$ \\
\hline Nelson A. S. Gimenes & 1 & $4.34 \%$ \\
\hline Adelina de Oliveira Novaes & 1 & $4.34 \%$ \\
\hline Luciana Barbosa Musse & 1 & $4.34 \%$ \\
\hline Anamérica Prado Marcondes & 1 & $4.34 \%$ \\
\hline Sandra Ferreira Acosta & 1 & $4.34 \%$ \\
\hline Almerindo Janela Afonso & 1 & $4.34 \%$ \\
\hline Ana Cristina Muniz Décia & 1 & $4.34 \%$ \\
\hline Rivailda Silveira Nunes de Argollo & 1 & $4.34 \%$ \\
\hline Ana Cristina Oliver & 1 & $4.34 \%$ \\
\hline Mary Ângela Teixeira Brandalise & 1 & $4.34 \%$ \\
\hline Clícia Bührer Martins & 1 & $4.34 \%$ \\
\hline Claudia Maffini Griboski & 1 & $4.34 \%$ \\
\hline Elisa Antonia Ribeiro & 1 & $4.34 \%$ \\
\hline Ângelo Ricardo de Souza & 1 & $4.34 \%$ \\
\hline Douglas Danilo Dittrich & 1 & $4.34 \%$ \\
\hline Maria Angélica Rodrigues Martins & 1 & $4.34 \%$ \\
\hline Cileda de Queiroz e Silva Coitinho & 1 & $4.34 \%$ \\
\hline Maria Alba de Souza & 1 & $4.34 \%$ \\
\hline
\end{tabular}

Fonte: os autores (2014)

Dos três autores que aparecem com mais de duas publicações destacam-se Clarilza Prado de Sousa, com três artigos (SOUSA, 2000; SOUSA, 2006; SOUSA; MARCONDES; ACOSTA, 2008), seguida por Bernardete A. Gatti (GATTI, 2000; GATTI, 2006) e Zacarias Gama (GAMA, 2010; GAMA, 2012), com dois artigos cada. A maior produção dos referidos autores sobre a temática da avaliação institucional em relação aos demais, vai de encontro com o próprio interesse de pesquisa destes autores, conforme pode ser visualizado em seus 
Avaliação Institucional: mapeamento e análise das concepções de qualidade e melhoria nas produções da revista Estudos em Avaliação Educacional (1990-2013)

currículos lattes, onde se constata que há algum tempo eles tem se dedicado a produção da temática em questão, caso, por exemplo de Clarilza Prado de Sousa e Zacarias Gama, que tiveram suas pesquisas de mestrado e doutorado relacionadas à avaliação educacional. Sem contar as contribuições empreendidas por Bernadete Gatti, desde a década de 1970, para a área da avaliação educacional no Brasil (GATTI, 1977).

Sobre as instituições dos autores dos artigos, a predominância foi de autores ligados à Pontifícia Universidade Católica de São Paulo (PUC-SP), totalizando dez autores, precedida pela Fundação Carlos Chagas, com cinco autores. Há ainda três autores da Universidade Federal da Bahia (UFBA) e dois da Universidade Estadual de Ponta Grossa (UEPG). As outras instituições aparecem relacionadas apenas a um autor cada, conforme mostra Tabela 3. Cabe salientar que também nesta tabela o número de instituições supera o número de autores e de artigos devido existirem autores ligados a mais de uma instituição, ou que escreveram um mesmo artigo, mas pertencem a instituições diferentes.

Tabela 3 - Distribuição dos autores dos artigos por instituições

\begin{tabular}{lcc}
\hline \multicolumn{1}{c}{ INSTITUIÇÃO } & $\begin{array}{c}\text { QUANTIDADE DE AUTORES RE- } \\
\text { LACIONADOS }\end{array}$ & PORCENTAGEM \\
\hline PUC - SP & 10 & $37.03 \%$ \\
\hline Fundação Carlos Chagas & 5 & $18.51 \%$ \\
\hline UFBA & 2 & $7.40 \%$ \\
\hline UEPG & 2 & $7.40 \%$ \\
\hline Universidade de Brasília - UNB & 1 & $3.70 \%$ \\
\hline Faculdade de Educação da USP & 1 & $3.70 \%$ \\
\hline Universidade do Minho (Portugal) & 1 & $3.70 \%$ \\
\hline Universidade Estadual da Bahia & 1 & $3.70 \%$ \\
\hline $\begin{array}{l}\text { Universidade Estadual do Rio de } \\
\text { Janeiro - UERJ }\end{array}$ & 1 & $3.70 \%$ \\
\hline $\begin{array}{l}\text { Secretaria do Estado da Educação } \\
\text { de Minas Gerais }\end{array}$ & 1 & $3.70 \%$ \\
\hline Instituição não informada & 6 & $22.22 \%$ \\
\hline
\end{tabular}

Fonte: os autores (2014)

Pode-se observar a predominância de artigos vinculados a uma instituição de ensino e a um centro de pesquisa situados na região sudeste do Brasil, no estado de São Paulo. Este dado também tem aparecido em outros trabalhos que tratam de artigos publicados em revistas. Poltronieri e Calderón (2012), ao analisarem produções do mesmo periódico, porém com foco diferente, apresentam resultado semelhante, ao demonstrarem que a concentração de artigos pesquisados se encontra em instituições como a Fundação Carlos Chagas. Também Borges e Calderón (2011) demonstram, em estudo sobre a produção em avaliação educacional publica- 
da na revista Ensaio: Avaliação e Políticas Públicas em Educação, que a maioria dos artigos foi produzida por instituições localizadas na região sudeste do país. Além disso, há que se destacar que a PUC-SP tem, desde o início da década de 1980, formado mestres e doutores em seus programas de pós-graduação em educação com trabalhos voltados especificamente para a área da avaliação, onde se encontram vinculados pesquisadores como Bernardete A. Gatti, Clarilza Prado de Sousa, Ana Maria Saul, Isabel Cappelletti (in memoriam) e Mere Abramowicz, cujas produções tem sido referências para as pesquisas em avaliação educacional no Brasil, conforme assinalam Teixeira (2006) e Uler (2010).

O mapeamento permitiu a distribuição dos artigos a partir do nível de ensino a que se referiam, conforme Tabela 4.

\section{Tabela 4 - Distribuição dos artigos por níveis de ensino}

\begin{tabular}{lc}
\hline \multicolumn{1}{c}{ NÍVEL DE ENSINO } & QUANTIDADE DE ARTIGOS \\
\hline Educação Superior & 18 \\
\hline Educação Básica/Escolar & 4 \\
\hline Ambos & 1 \\
\hline Total geral & 23 \\
\hline
\end{tabular}

Fonte: os autores (2014)

Pode-se perceber a predominância, dentre os textos selecionados, de artigos que discutem a questão da avaliação institucional focalizando a educação superior. Dezoito dos artigos selecionados tratam deste nível de ensino, enquanto apenas quatro tratam da educação básica, e um fala de instituições educacionais como um todo. Acredita-se que isso ocorra devido o termo "avaliação institucional" estar diretamente relacionado à origem dos processos de avaliação institucional em nosso cenário educacional, que encontrou no seio das universidades lugar propício para seu desenvolvimento em meados da década de 1990 (BALZAN; DIAS SOBRINHO, 1995), e que veio mais tarde a se consolidar a partir da criação do Sistema Nacional de Avaliação da Educação Superior (SINAES), em 2004, relacionado à avaliação de instituições de ensino superior.

Esse dado se vê corroborado no estudo de Moraes (2008), que ao pesquisar no banco de dissertações e teses da Coordenação de Aperfeiçoamento de Pessoal de Nível Superior (CAPES) sobre o tema da avaliação institucional, no período de 1987 a 2006, encontra um total de 264 trabalhos, 256 destes discutiam a temática no âmbito da educação superior e apenas oito referiam-se à avaliação institucional da escola básica. Também Silva (2013) ao analisar os trabalhos e pôsteres apresentados nos Grupos de Trabalho (GTs) ANPED, no período 
Avaliação Institucional: mapeamento e análise das concepções de qualidade e melhoria nas produções da revista Estudos em Avaliação Educacional (1990-2013)

de 2000 a 2010, demonstra que a maior preocupação das pesquisas quando se discute a temática da avaliação institucional se encontra na educação superior, fato este que, segundo o autor “pode ser justificado pela própria natureza da ANPEd e pelos lugares de origens dos/as pesquisadores/as que habitam seus fóruns", o que ocorreu "[...] em virtude dos contornos da avaliação da pós-graduação empreendida pela Coordenação de Aperfeiçoamento de Pessoal de Nível Superior - CAPES - e posteriormente da avaliação das universidades como um todo dentro do SINAES" (SILVA, 2013, p. 346).

\section{As concepções de qualidade e melhoria nas produções da revista Estudos em Avaliação}

\section{Educacional}

Ao analisar as concepções dos autores dos artigos selecionados sobre qualidade da educação e melhorias, pode-se perceber que os dois conceitos estão bastante relacionados e que, de modo geral, a melhoria aparece como a concretização daquilo que se entende por qualidade. Além disso, um aspecto comum entre a maioria dos artigos é o conceito de qualidade ligado ao cumprimento pela instituição de sua função social. Na maior parte das vezes a qualidade aparece relacionada ao papel da universidade frente à sociedade.

Masetto (1990) destaca a importância de que a universidade/educação cumpra seu papel social, sendo um bem público produtor de benefícios que atingem toda a sociedade, devendo ser avaliada pela eficácia social de suas atividades e pela eficiência de seu funcionamento. Dessa forma, a atuação da universidade deve ocorrer de acordo com as demandas e transformações características do movimento da sociedade. $\mathrm{O}$ autor afirma, ainda, que a instituição pode identificar meios de se tornar instrumento político-pedagógico produtor de conhecimento que seja veiculado e enriquecido pelas classes sociais historicamente marginalizadas no que se refere ao processo político e cultural nacional. Melhoria seria, então, melhor cumprir sua função social perante a sociedade em que está inserida.

No artigo de Saul (1990) a qualidade também é entendida em seus aspectos políticos, como busca da relevância de um projeto de universidade, e não como um modelo "ideal", definido aprioristicamente. A autora afirma que definir qualidade implica reflexão acerca de qual é o papel social da universidade em função de uma sociedade mais justa, democrática e moderna. Qualidade é, portanto, considerada como a relevância social do que é produzido na instituição, construída e reconstruída pelo coletivo que compõe a mesma, em intercâmbio com as demais instituições universitárias e com as instâncias que definem a política e avaliam a universidade. Nessa perspectiva, a autora demonstra compreender como melhoria o processo 
de transformação da universidade que se tem para a universidade que se necessita, transformação esta em prol da construção de uma sociedade justa, democrática e direcionada para o desenvolvimento científico e tecnológico.

Também Amorim e Sousa (1994, p. 128), sobre o conceito de qualidade, afirmam ser um "Conceito de sentido resultante das relações de integração e de conflito entre as instâncias e setores que integram a atividade educativa. Expressa, em última instância, o projeto de sociedade que se tem por norte”. Os autores fazem uma interpretação do conceito de qualidade como eficácia social das atividades e eficiência do funcionamento da instituição de educação e de melhoria como a possibilidade de que a universidade redefina sua atuação levando em conta seu compromisso com a sociedade.

Sousa (2000) também demonstra que a qualidade está relacionada à efetividade pela instituição de sua função social, ao seu impacto e participação na melhoria da qualidade de vida. Porém, a autora aponta, ainda, que o objeto da avaliação institucional vai desde a organização do currículo até as condições materiais e relações de trabalho ou com os alunos na instituição, considerando também o grau de satisfação destes, e podendo ter como foco de análise o contexto psicopedagógico da instituição, o contexto da formação profissional ou o contexto da formação do cidadão. Entende-se que estes fatores indicam qualidade.

Em outro artigo Sousa (2006) relaciona, ainda, a qualidade do ensino com a construção de um clima acadêmico de difusão do saber e formador de cidadãos éticos, compromissados com o desenvolvimento do país, e com a implantação pela universidade dos princípios e das bases da educação nacional. Ela também propõe que haja dois indicativos como critério para a análise na autoavaliação, realizando-se uma análise comparativa, tendo como referência o ideal, o modelo de universidade proposto no Plano de Desenvolvimento Institucional (PDI) e, ao mesmo tempo, considerando a instituição que está sendo construída no cotidiano escolar, vivenciado pela comunidade universitária, indicando a distância entre as ações cotidianas e o modelo idealizado.

Gatti (2000), por sua vez, coloca qualidade como um conceito com múltiplos significados, pois as "qualidades" variam de acordo com as necessidades e condições a serem buscadas nos processos avaliativos. A autora demonstra, ainda, uma compreensão de qualidade para além do suprimento das necessidades do mercado de trabalho, mas também como o papel que a universidade tem a desempenhar como possibilitadora de abertura de novos horizontes, de transformações sociais que possam ser significativas para a maioria das pessoas. Dessa maneira, compreende melhorias como possibilidades de soluções e aprimoramentos, novos caminhos pensados a partir dos resultados da situação que se tem. 
Avaliação Institucional: mapeamento e análise das concepções de qualidade e melhoria nas produções da revista Estudos em Avaliação Educacional (1990-2013)

Em outro artigo Gatti (2006) coloca a universidade como bem público, que tem um papel sociocultural e científico, sendo voltada para ações de ensino, de estudos ou de intervenções, destinadas à construção, reconstrução, difusão e ampliação de conhecimentos cujos efeitos socioculturais sejam, de alguma forma, relevantes para a constituição de uma sociedade mais equitativa. Melhoria, neste contexto, parece ser compreendida como a possibilidade de a universidade, como instituição formadora de gerações humanas em uma certa direção civilizatória, comportar uma perspectiva sobre o conhecimento que se constrói e que se transmite como meio para viver melhor num coletivo compartilhado.

A relação entre qualidade e o cumprimento pela instituição educacional de sua função social aparece, ainda, em outros artigos analisados, mesmo que de modo sucinto. Décia e Argollo (2010) evidenciam entender por qualidade alcançar o que está estabelecido no planejamento, missão e função social da instituição. Oliver (2010), também afirma a educação como bem público, com responsabilidade pública e finalidade social. Griboski (2012) demonstra entender a qualidade a partir da relação que se estabelece entre universidade e sociedade. A autora afirma a importância de uma formação no sentido da construção da cidadania, para além do suprimento das demandas neoliberais, mercadológicas. Além disso, Ribeiro (2012), também assume percebe qualidade como o fato de que a instituição cumpra sua missão e se desenvolva ao máximo. Para a autora, deve haver busca contínua pela instituição de ensino superior da qualidade no desempenho acadêmico, pelo aperfeiçoamento constante do planejamento e da gestão universitária e pelo fortalecimento progressivo dos compromissos sociais na prestação de contas à sociedade.

Há, no entanto, alguns autores que apresentaram a questão de outras formas. Vianna (2004), por exemplo, deixa notar em seu artigo uma visão de qualidade como prática educativa em que se efetive a interação entre professor e aluno, e na qual o corpo docente atualize constantemente seus conhecimentos, visando promover a profissionalização dos alunos.

Já no artigo de Afonso (2010) sobre autoavaliação da escola pública portuguesa, o conceito não é definido, pois o autor faz referência à diversidade contextual de cada escola, e às divergências de valores que ocorrem mesmo dentro de uma escola, devido à heterogeneidade dos envolvidos no processo educativo. No entanto, o autor afirma que "não é qualquer forma ou modalidade de avaliação institucional (e de autoavaliação) que pode dar conta, com a objectividade e justiça possíveis, da multidimensionalidade e complexidade das escolas públicas enquanto instituições (e organizações) educativas específicas” (AFONSO, 2010, p. 356). Sobre melhoria, o artigo demonstra a compreensão de que esta deve se dar em âmbito científico, pedagógico e democrático. 
Outros artigos que tratam da avaliação na escola relacionam qualidade da educação à efetivação da aprendizagem dos alunos. Souza e Dittrich (2012) compreendem, no artigo analisado, qualidade como o bom rendimento dos alunos, articulado com a democratização da educação. A questão da melhoria, neste caso, pode ser compreendida como a maior aprendizagem dos alunos, a partir de uma definição coletiva do mínimo necessário a ser aprendido. Esta concepção converge com a de Souza (1995), que relaciona qualidade à aprendizagem e bom desempenho dos alunos, entendendo como melhoria a melhor promoção desta aprendizagem.

De modo sintético, pode-se concluir que as concepções sobre qualidade e melhoria da educação nos artigos analisados concentram-se fortemente em dois focos. A grande maioria (MASETTO, 1990; SAUL, 1990; AMORIM; SOUSA, 1994; SOUSA, 2000; GATTI, 2000; 2006; SOUSA, 2006; DÉCIA; ARGOLLO, 2010; OLIVER, 2010; GRIBOSKI, 2012; RIBEIRO, 2012) remete-se à qualidade enquanto cumprimento pela instituição de sua função social, considerando aspecto importante a relevância para a sociedade das atividades realizadas na e pela universidade. Por sua vez, há um conjunto significativo de artigos (VIANNA, 2004; SOUZA; DITTRICH, 2012; SOUZA, 1995) que relacionam a qualidade e melhoria ao rendimento e à formação dos alunos.

\section{A relação entre avaliação institucional com a melhoria da qualidade da educação nas produções da revista Estudos em Avaliação Educacional}

No que diz respeito à relação da avaliação institucional com a melhoria da qualidade da educação, um ponto de consenso presente na maior parte dos artigos analisados é a concepção de avaliação institucional como possibilidade de se ter uma "imagem" da situação da instituição, visando analisar o que pode ou precisa ser melhorado, e então pensar e planejar ações com este objetivo.

Masetto (1990) em seu artigo defende a avaliação institucional como atividade contínua, que cria melhores condições à universidade de atingir seus objetivos e às exigências do contexto no qual está inserido, em contraposição à ideia de avaliação como máquina fotográfica, que tira uma fotografia da universidade, como se esta fosse estática e cristalizada, estando para sempre na mesma condição. Para o referido autor, "Uma avaliação institucional está voltada para produzir transformações, isto é, evolução, crescimento, desenvolvimento da Universidade e não para cristalizá-la no momento de sua avaliação" (MASETTO, 1990, p. 10). 
Avaliação Institucional: mapeamento e análise das concepções de qualidade e melhoria nas produções da revista Estudos em Avaliação Educacional (1990-2013)

Ele ressalta o dever da avaliação de contribuir com a universidade para a redefinição de sua atuação, de acordo com seu compromisso perante a sociedade.

Masseto (1990) afirma, ainda, que ao contemplar os eixos de análise das relações entre universidade e sociedade (analisando a universidade em função da realidade social, política e econômica do país), entre universidade e Estado (averiguando a autonomia da universidade para definir seu próprio projeto institucional) e entre a organização institucional e o processo de produção e disseminação do conhecimento, esta proposta de avaliação institucional poderá retratar o momento institucional e fornecer subsídios para encaminhamentos de mudanças que forem necessárias. Dessa forma, a avaliação institucional é entendida como processo "potencial de produzir conhecimento sobre uma dada realidade e subsidiar uma prática transformadora" (MASETTO, 1990, p. 11).

No artigo de Saul (1990) a avaliação institucional aparece como fator que deve levar os envolvidos no processo educativo à reflexão crítica sobre sua atuação e ao levantamento de possíveis alternativas de ação, tendo compromisso com a transformação da universidade que se tem para a universidade que se necessita, sendo esta transformação direcionada à construção de uma sociedade democrática, justa e voltada para o desenvolvimento científico e tecnológico. Para a autora:

O objetivo da avaliação institucional deve ser levar ao engajamento dos agentes da ação educativa na instituição, num processo de autocrítica e transformação, comprometendo-os com o delineamento e com a execução de um projeto de universidade onde a participação garanta o envolvimento daqueles que vivem o cotidiano da universidade, na sua construção e/ou reconstrução (SAUL, 1990, p. 18).

Dessa maneira, a partir de um "retrato sem retoques" da situação da universidade, tendo clareza de qual é a função social da universidade, o coletivo envolvido em sua construção poderá pensar juntos meios de chegar à universidade que almejam, elaborando um projeto de ação para alcançá-la, em prol de uma sociedade mais justa e democrática, para a qual a produção científica e tecnológica tenha relevância.

Amorim e Sousa (1994) demonstram compartilhar desta mesma ideia, pois consideram que a avaliação institucional deve ser um processo construído coletivamente, a partir das concepções dos envolvidos a respeito da função social da universidade, sendo um instrumento político que pode gerar transformação por meio da reflexão acerca do que se faz na universidade e do que se poderia fazer para torná-la um instrumento político-pedagógico produtor de conhecimento científico que precisa ser veiculado e enriquecido pelas classes sociais historicamente marginalizadas do processo cultural e político da nação. 
A avaliação institucional, nesta perspectiva, tem uma dimensão revolucionária, por possibilitar a articulação da universidade com os problemas reais da sociedade. A partir dela, poderá se obter o retrato do momento institucional, subsídio para encaminhamentos de transformações necessárias. No entanto, para que seja um instrumento efetivo de transformação, o processo avaliativo deve ser construído a partir dos confrontos entre as diferenças. Amorim e Sousa (1994) ressaltam que esta avaliação é, portanto, um instrumento político, mas que pode tanto servir à universidade, para reconstruir suas teorias e práticas, como pode ser um instrumento discriminatório, burocrático e emperrador da criação e inovação da vida acadêmica.

Também Gimenes (2007) considera que a avaliação formativa e diagnóstica, juntamente com a participação da comunidade acadêmica tem enorme potencial para transformarse em importante instrumento para a identificação das potencialidades e dos aspectos não desenvolvidos das instituições de educação superior, criando, dessa forma, condições para a busca permanente de melhorias em relação às suas ações. Por meio da reflexão embasada nos resultados das avaliações, pensa-se soluções e aprimoramentos. O autor afirma que,

[...] A auto-avaliação é um processo permanente de autoconhecimento e de autocrítica da instituição, constituindo-se em instrumento fundamental para a reflexão de sua identidade institucional, bem como de auxílio para a tomada de decisões quanto às suas diferentes atividades, sejam elas pedagógicas, administrativas, de extensão ou de pesquisa (GIMENES, 2007, p. 239).

Já no artigo de Gatti (2000) a avaliação institucional é mostrada como processo que ocorre a partir de referenciais de qualidade relativos, subjetivos aos sujeitos envolvidos, devendo ter seus objetivos bem definidos, levando em consideração seu contexto e visando contribuir para que, percebendo as necessidades da instituição, elabore-se possibilidades de soluções e aprimoramentos. De acordo com a autora, por meio da avaliação institucional as instituições de educação superior podem compreender seus problemas no que se refere a questões acadêmicas e estruturais, buscando então soluções, alternativas, renovações e aperfeiçoamentos. Assim, a avaliação pode contribuir para que a instituição não fique estagnada, mas elabore aperfeiçoamentos contínuos, adequados às suas necessidades.

Porém, em outro artigo de sua autoria, Gatti (2006) introduz um novo aspecto à sua análise, afirmando que para que gere melhorias para a universidade e para a sociedade, é necessária uma perspectiva participativa e dialógica de avaliação que, para além dos dados quantitativos, permita reflexão sobre o cumprimento pela universidade de seu papel científico e sociocultural. A autora ressalta que:

Somente considerando o papel da universidade na perspectiva de produzir e transmitir conhecimento como meio para viver melhor num coletivo compartilhado, poderão ser escolhidos meios e instrumentos para uma avaliação institucional que poderá ajudar em reais avanços socioeducacionais, se for utilizada de forma que leve à construção de visões mais integradas 
Avaliação Institucional: mapeamento e análise das concepções de qualidade e melhoria nas produções da revista Estudos em Avaliação Educacional (1990-2013)

acerca de seu percurso histórico-institucional, em seus envolvimentos concretos (GATTI, 2006, p. 10).

Vianna (2004), por sua vez, coloca que a avaliação gera conhecimentos fundamentais para o planejamento e para a ação institucional. Afirma, ainda, que ela também pode ser um instrumento para que a instituição defina sua política de admissão de professores, selecionando não apenas os mais capacitados, mas aqueles que serão capazes de interagir mais facilmente com o corpo discente.

Também Décia e Argollo (2010), afirmam a importância de a avaliação fornecer subsídios e prioridades a serem considerados no planejamento. Em sua concepção, a avaliação pode servir como diagnóstico, podendo-se, a partir disso, elaborar estratégicas para o aumento da qualidade da educação da instituição. As autoras defendem, ainda, a avaliação institucional de cunho participativo e formativo que possibilite um repensar de ações, com vistas à efetividade da gestão e da melhoria do ensino.

Já Sousa (2000), levando em conta os diferentes níveis de ensino, indica que os resultados da avaliação institucional devem subsidiar o aperfeiçoamento de decisões sobre a trajetória escolar, conteúdos e aprendizagens fundamentais, direção da formação escolar, estratégias de ensino. Em outro artigo, Sousa (2006), tratando da Educação Superior, afirma que um processo avaliativo somente se realiza quando subsidia o processo de tomada de decisões, fornecendo uma possibilidade bastante significativa de dados a serem coletados e analisados, que faz com que ele tenha caráter formativo e formador. A autora ainda ressalta que a avaliação deve contribuir para reforçar a identidade da instituição. Em sua concepção, ela permite que a instituição se compare com outras instituições e com sua própria história, o que possibilita que afirme a própria identidade e trace as metas para o futuro, definindo sua função social. Enfim, é defendida uma proposta de autoavaliação que, para além da regulação, perpasse os diferentes âmbitos e sujeitos da universidade, permitindo uma reflexão que gere subsídios à tomada de decisões.

No artigo de Sousa, Marcondes e Acosta (2008), está presente a concepção de que a avaliação institucional deve ser um processo de elaboração de conhecimento acerca da instituição, interpretado pelos diferentes agentes envolvidos, e que deve servir de base apara a tomada de decisões na instituição. Para as autoras, os resultados das avaliações poderão ser apropriados pela comunidade para orientar seu desenvolvimento e processo avaliativo deve ser conduzido com vistas a embasar a tomada de decisões.

Oliver (2010) demonstra compartilhar desta ideia, entendendo que a avaliação institucional (a interna juntamente com a externa), pode proporcionar maior conhecimento sobre a 
instituição de educação superior a todos os envolvidos, para que esses possam adequar seu trabalho às demandas, visando melhorias na qualidade da educação. De acordo com a autora, uma avaliação que tenha como princípios a participação, o engajamento e o envolvimento de todos os interessados, além da transparência do processo, visando a sua credibilidade, poderá garantir o comprometimento da direção e de toda a comunidade quanto à execução de ações de curto, médio e longo prazo, para a melhoria da unidade. Além disso, ela descreve no artigo uma situação específica de avaliação institucional, e afirma que esta teve por objetivo promover um maior conhecimento da própria instituição, para que se possa refletir sobre as fragilidades e potencialidades e desencadear um processo consciente de crescimento e melhoria da qualidade.

Ribeiro (2012) também coloca a avaliação institucional como instrumento para o autoconhecimento da instituição, permitindo identificar erros e acertos, vantagens, potencialidades e dificuldades, para embasar a tomada de decisões a partir do que foi identificado, objetivando melhoras. A autora vê a avaliação institucional (AI) em seu sentido formativo, como instrumento de reflexão para a tomada de decisões visando melhorar sempre:

Colocando o foco da AI no seu sentido formativo, mais que um simples processo informativo e estabelecendo um caráter educativo, é que será possível instaurar um sentido avaliativo com o objetivo de buscar evidenciar o que é preciso mudar e o que é preciso fortalecer e ampliar para a obtenção do sucesso relacionado à qualidade da educação superior (RIBEIRO, 2013, p. 176).

Martins e Coutinho (2013) seguem a mesma ideia, ressaltando o caráter político e pedagógico da autoavaliação institucional, por permitir observar a situação da instituição, compreender suas dificuldades e melhorar suas condições. Elas enxergam a autoavaliação institucional como um processo participativo, formativo e formador, que procura produzir uma visão de conjunto das instituições de educação superior, sendo o objetivo conhecer para compreender suas dificuldades e equívocos, para potencializar as condições de desenvolver, com melhor qualidade, os agentes, a instituição e os contextos.

Já Griboski (2012, p. 181) analisa o Exame Nacional de Desempenho de Estudantes (ENADE) e o indica “como um dos elementos imprescindíveis para a avaliação da educação superior, pela forma de obtenção de dados válidos na organização e reorganização dos currículos e pela indução da prática formativa esperada dos cursos de graduação". A autora afirma sobre o Enade que se trata de um ciclo avaliativo que permite ao avaliador e ao avaliado traçarem rumos, metas e inovação na busca da qualidade. Indica-o como um elemento indutor da qualidade da educação superior, a partir das contribuições que os resultados das avaliações podem trazem para o aprimoramento do curso e para a própria formação dos estudantes de 
Avaliação Institucional: mapeamento e análise das concepções de qualidade e melhoria nas produções da revista Estudos em Avaliação Educacional (1990-2013)

graduação. Afirma que por ser um instrumento de participação social que convoca todos os estudantes a darem sua percepção sobre os cursos de graduação, o Enade possibilita o acompanhamento da qualidade.

Para a autora, o Enade, juntamente com a avaliação de cursos e das instituições, e os indicadores de qualidade, pode oferecer informações importantes à reflexão por parte de todos os envolvidos sobre aspectos que podem ou precisam ser melhorados na instituição. É destacado, ainda, o aspecto formativo desta avaliação e o fato de seus resultados servirem de subsídio para a tomada de decisões:

$\mathrm{O}$ aspecto formativo da avaliação pressupõe que seus resultados sirvam de referencial para o aprimoramento da gestão das instituições e que sejam disponibilizadas as informações suficientes às tomadas de decisões e ao replanejamento das ações e investimentos, com base na avaliação interna e externa realizada periodicamente" (GRIBOSKI, 2012, p. 191).

[...] as informações resultantes do processo de avaliação subsidiam a tomada de decisão dos gestores sobre mudanças necessárias no curso, como a revisão de currículos, de projetos e de programas que venham a incidir em novas práticas e em tecnologias educacionais aplicadas à necessária formação do estudante (GRIBOSKI, 2012, p. 192).

Há ainda, o artigo de Gama (2010), que faz uma análise de cunho sociológico da autoavaliação institucional após o Sinaes, em duas universidades do Rio de Janeiro. O autor afirma que as políticas públicas para avaliação não são neutras, envolvem valores, ideologias e interesses, e que há falta de análise crítica sobre a teoria de avaliação institucional. É concluído que:

Conforme nossas investigações, foi possível constatar que a avaliação institucional tende gradualmente a enclausurar as universidades mesmo que a considerem um sistema aberto, dinâmico e dialético. Instituída como sistema, a avaliação deve ir se impondo por meio do jogo das regulações e das autorregulações de modo constringente em favor dos interesses subjacentes às políticas de governo e de Estado, a serviço do processo sociometabólico do capital. A avaliação, todavia, em nível teórico e prático, é pensada de modo que se apresente dissimuladamente como democrática, participativa e capaz de criar redes interpessoais de solidariedade, e de estar comprometida com a construção voluntária de uma "universidade moderna" sempre referenciada a critérios de 'verdade social'(p. 41).

Os artigos até o momento analisados tratavam especificamente da avaliação institucional na educação superior, ou nos diferentes níveis de ensino (SOUSA, 2000). No entanto, há ainda os quatro artigos que tratam desta questão com foco nas escolas (SOUZA, 1995; AFONSO, 2010; BRANDALISE; MARTINS, 2011; SOUZA; DITTRICH, 2012).

Afonso (2010), ao tratar dos processos de autoavaliação nas escolas públicas portuguesas, afirma que a avaliação institucional pode ser formativa e emancipatória, conduzindo a uma melhoria global e sustentada de todos os dispositivos, estratégias e práticas que visem uma educação de qualidade, simultaneamente, em termos científicos, pedagógicos e democráticos. Em sua concepção, a avaliação formativa deve ocorrer em diálogo, transparência e in- 
terdisciplinarmente, permitindo reflexão crítica sobre a realidade escolar visando uma melhoria global.

Souza e Dittrich (2012) também tratam da avaliação institucional escolar, colocando que por meio dela é possível conhecer os progressos e dificuldades dos alunos, estabelecendo coletivamente conhecimentos mínimos necessários a estes, e que assim pode-se pensar, pais, gestão e professores, em soluções para alcançar melhorias na qualidade da educação. Para os autores, a avaliação possibilita conhecer melhor os problemas institucionais, potencializando suas soluções, e “[...] as escolas podem e devem desenvolver mecanismos próprios de avaliação, que auxiliem os seus processos de organização e gestão, com vistas ao desenvolvimento de mais qualidade na educação pública” (p. 45).

Brandalise e Martins (2011) tratam de uma pesquisa de campo sobre as concepções diferentes de gestores acerca de um projeto avaliativo implantado nas escolas do município. "O resultado da avaliação institucional realizada, segundo os depoimentos das equipes gestoras, apontou alguns aspectos que a escola precisaria levar em consideração para elaborar seus planos e projetos de trabalho" (BRANDALISE; MARTINS, 2011, p. 449). Apesar de não definirem os conceitos de avaliação institucional, qualidade e melhoria, as autoras concluem que a comunidade escolar reconhece a importância da avaliação institucional para a melhoria do trabalho nas escolas públicas, porém há muita dificuldade de integrar essa forma de avaliação nas atividades cotidianas da instituição escolar.

Por fim, Souza (1995) ao analisar um processo de avaliação desenvolvido nas escolas de Minas Gerais aponta que este promoveu melhor conhecimento da realidade escolar e de suas necessidades, possibilitando que órgãos responsáveis traçassem metas para a melhoria de aspectos que interferem na qualidade da educação. De acordo com a autora, a avaliação visa identificar pontos críticos da realidade educacional para, então, implantar e acompanhar ações para a melhoria, necessária para que se atinja a qualidade da educação. A autora afirma, ainda, que são propósitos de uma avaliação institucional tendo em vista a qualidade do ensino nas escolas estaduais:

I. conhecer o desempenho dos alunos em aspectos cognitivos dos conteúdos curriculares; II. levantar dados e informações para servirem de subsídios na tomada de decisões sobre o desenvolvimento do processo de ensino;

III. identificar, nos conteúdos curriculares, pontos críticos que necessitam maior atenção e requerem intervenção imediata e prioritária para a melhoria da aprendizagem;

IV. fornecer, a partir dos dados levantados, subsídios para que os professores possam atuar com maior eficiência na condução do processo de ensino e a Secretaria da Educação possa colaborar para maior eficiência do Sistema (SOUZA, 1995, p. 26). 
Avaliação Institucional: mapeamento e análise das concepções de qualidade e melhoria nas produções da revista Estudos em Avaliação Educacional (1990-2013)

A partir do exposto, nota-se que a avaliação institucional é tratada pelos autores analisados como um instrumento que pode gerar um diagnóstico da instituição nos seus diferentes âmbitos, e que este diagnóstico pode inclusive servir de base para processos de tomada de decisões na própria instituição. Assim sendo, por meio da avaliação, têm-se um parâmetro da realidade, sendo, portanto, possível à formulação de ações que busquem melhorias na qualidade da educação.

\section{Considerações finais}

O artigo analisou a produção sobre Avaliação Institucional divulgado na revista Estudos em Avaliação Educacional no período de 1990 a 2013. Para isso foi realizado um estudo bibliográfico em bases de dados da revista disponível online no site da Fundação Carlos Chagas.

Os resultados apontam alguns aspectos sobre a produção da revista analisada a respeito da temática investigada, dentre os quais se destacam que:

a) Há maior concentração de artigos relacionados ao tema estudado a partir dos anos 2000 (Tabela 1), sendo 2010 e 2012 os anos que tiveram maior número de publicações sobre a temática da avaliação institucional.

b) O conjunto de autores dos artigos selecionados é bastante diverso, totalizando vinte e sete autores diferentes, dentre os quais apenas três tiveram autoria em mais de um artigo, são eles Clarilza Prado de Sousa, Bernerdete Gatti e Zacarias Gama (Tabela 2).

c) Há predominância de autores ligados a instituições e centros de pesquisas situados na região sudeste do Brasil, destacando-se a Pontifícia Universidade Católica de São Paulo e a Fundação Carlos Chagas (Tabela 3).

d) Os artigos sobre avaliação institucional tratam predominantemente deste tema no âmbito do Ensino Superior, e apenas uma pequena parte analisa as questões focalizando a Educação Básica (Tabela 4).

Na pesquisa a avaliação institucional foi compreendida a partir da organização proposta por Freitas et al. (2009), onde os autores postulam três níveis de avaliação integrados entre si, a avaliação da aprendizagem, a avaliação institucional e a avaliação de sistemas. A avaliação institucional deve, segundo os autores, ser um ponto de encontro entre os dados provenientes da avaliação dos alunos realizada pelos professores e a realizada pelo sistema.

Retratando a situação da instituição, a partir de seus diferentes aspectos, a avaliação institucional permite que a mesma reveja seus objetivos e reflita sobre possíveis estratégias para alcançá-los. A partir da realidade que se tem, projetam-se coletivamente ações que possam trazer melhorias, que estejam na direção dos objetivos estabelecidos previamente. 
Nessa perspectiva entende-se que a avaliação deve propiciar melhorias às instituições de ensino, ela pode ser assim utilizada como meio de reflexão para a tomada de decisões, ou seja, que permita pensar a realidade que se tem, aonde se quer chegar e o que fazer para alcançar o que se deseja. Deste modo, uma avaliação que busque verdadeiramente proporcionar parâmetros da realidade educacional necessita explorar todos os aspectos que compõem o sistema, e perceber como cada um impacta em sua qualidade.

Já sobre a questão principal da pesquisa, nota-se, tanto nos artigos que tratam do Ensino Superior quanto nos que se relacionam à Educação Básica, forte relação entre avaliação institucional e o processo de diagnóstico da instituição, dando base à tomada de decisões. Entendendo-se que a avaliação institucional deve fornecer subsídios para que se reflita sobre a situação da instituição e possa se pensar em ações para a melhoria da qualidade. Por meio da avaliação pode-se conhecer as necessidades, falhas e potencialidades da instituição, e a partir do que se tem pensar melhorias possíveis. Ressalta-se, ainda, que a qualidade, na maior parte dos artigos, aparece fortemente relacionada com o cumprimento pela instituição de sua função social, e em outra parte aparece associada ao rendimento e à formação dos alunos.

A partir da análise realizada, pode-se concluir que, de maneira geral, dois aspectos principais estão presentes na maior parte dos artigos pesquisados. O primeiro é a relação entre os resultados das avaliações com o processo de tomada de decisões, servindo de subsídio a ele, e o segundo é a possibilidade de se ter um diagnóstico por meio das avaliações, que permitam conhecer para saber as necessidades da instituição e então se pensar melhorias. Notase, ainda, que na discussão a respeito da relação entre avaliação institucional e melhorias na qualidade da educação se apresenta de modo semelhante, tanto nos artigos que tratam do Ensino Superior quanto nos que se referem à Educação Básica, obedecendo às especificidades próprias de cada nível de ensino, que vem se desenvolvendo desde o início dos anos 1980 na Educação Superior (BALZAN; DIAS SOBRINHO, 1995; BARREYRO; ROTHEN, 2008), e só mais recentemente começa a ganhar espaço também na escola básica (SOUSA, 2000; IANNONE, 2001; FREITAS et al., 2009).

\section{Referências}

AFONSO, Almerindo Janela. Políticas educativas e auto-avaliação da escola pública portuguesa: apontamentos de uma experiência. Estudos em Avaliação Educacional, São Paulo, v. 21, n. 46, p. 343-362, maio/ago. 2010. 
Avaliação Institucional: mapeamento e análise das concepções de qualidade e melhoria nas produções da revista Estudos em Avaliação Educacional (1990-2013)

AMORIM, Antônio; SOUSA, Sandra Maria Zakia Lian. Avaliação Institucional da Universidade Brasileira: questões polarizadoras. Estudos em Avaliação Educacional, São Paulo, n. 10, p. 123-136, 1994.

BALZAN, Newton Cesar; DIAS SOBRINHO, José (Orgs.). Avaliação Institucional: teoria e experiências. São Paulo: Cortez, 1995.

BARRETTO, Elba Siqueira de Sá; PINTO, Regina Paim. Avaliação na Educação Básica, 1990-1998. Brasília: MEC/Inep/Comped, 2001.

BARREYRO, Gladys Beatriz; ROTHEN, José Carlos. Para uma história da avaliação da educação superior brasileira: análise dos documentos do PARU, CNRES, GERES e PAIUB. Avaliação, Campinas; Sorocaba, SP, v. 13, n. 1, p. 131-152, mar. 2008.

BORGES, Regilson Maciel; CALDERÓN, Adolfo Ignacio. Avaliação educacional: o estado do conhecimento da Revista Ensaio: Avaliação e Políticas Públicas em Educação (19932008). Ensaio: aval.pol.públ.educ., Rio de Janeiro, v. 19, n. 70, p. 43-56, jan./mar. 2011.

BRANDALISE, Mary Ângela Teixeira; MARTINS, Clícia Bührer. Programa de avaliação institucional da educação básica do Paraná: da produção à implementação da política na escola. Estudos em Avaliação Educacional, São Paulo, v. 22, n. 50, p. 435-456, set./dez. 2011.

CANDAU, Vera Maria; OSWALD, Maria Luisa M. Bastos. Avaliação no Brasil: uma revisão bibliográfica. Cadernos de Pesquisa, São Paulo, n. 95, p. 25-36, nov. 1995.

DÉCIA, Ana Cristina Muniz; ARGOLLO, Rivailda Silveira Nunes de. Autoavaliação institucional da UFBA na era Sinaes: a experiência revisitada na Escola de Administração. Estudos em Avaliação Educacional, São Paulo, v. 21, n. 46, p. 387-404, maio/ago. 2010.

DIAS SOBRINHO, José (Org.). Avaliação Institucional da Unicamp: processo, discussão e resultados. Campinas, SP: UNICAMP, 1994.

DIAS SOBRINHO, José (Org.). Avaliação: políticas educacionais e reformas da educação superior. São Paulo: Cortez, 2003.

FREITAS, Luiz Carlos et al. Avaliação educacional: caminhando pela contramão. Petrópolis: Vozes, 2009.

GAMA, Zacarias. Avaliação das instituições públicas de ensino superior: direções e interesses subjacentes. Estudos em Avaliação Educacional, São Paulo, v. 21, n. 45, p. 33-44, jan./abr. 2010.

GAMA, Zacarias. Avaliação institucional: primeiras aproximações - teoria e crítica. Estudos em Avaliação Educacional, São Paulo, v. 23, n. 52, p. 254-272, maio/ago. 2012.

GATTI, Bernardete Angelina. Avaliação em sala de aula. In: CENP/SEESP. (Org.).

Formação de objetivos: avaliação. São Paulo: Secretaria da Educação do Estado de São Paulo, 1977. p. 27-40.

GATTI, Bernardete Angelina. Avaliação Institucional e Acompanhamento de Instituições de Ensino Superior. Estudos em Avaliação Educacional, São Paulo, n. 21, p. 93-108, 2000.

GATTI, Bernardete Angelina. Avaliação Institucional: processo descritivo, analítico ou reflexivo? Estudos em Avaliação Educacional, São Paulo, v. 17, n. 34, p. 7-14, maio/ago. 2006. 
GIMENES, Nelson A. S. Estudo metavaliativo do processo de auto-avaliação em uma Instituição de Educação Superior no Brasil. Estudos em Avaliação Educacional, São Paulo, v. 18, n. 37, p. 217-243, maio/ago. 2007.

GONÇALVES FILHO, Francisco. Enfoques de avaliação institucional em revista: um estudo da revista Avaliação (1996-2002). Dissertação (Mestrado em Educação) Universidade Estadual de Campinas, Campinas, 2003.

GRIBOSKI, Claudia Maffini. O Enade como indutor da qualidade da educação superior. Estudos em Avaliação Educacional, São Paulo, v. 23, n. 53, p. 178-195, set./dez. 2012.

IANNONE, Leila Rentroia. Avaliação institucional: relato de uma experiência. In:

CAPELLETTI, Isabel F. (Org.). Avaliação educacional: fundamentos e práticas. 2. ed. São Paulo: Editora Articulação Universidade/Escola, 2001.

MARCONI, Marina de Andrade; LAKATOS, Eva Maria. Fundamentos de metodologia científica. São Paulo: Atlas, 2003.

MARTINS, Maria Angélica Rodrigues; COUTINHO, Cileda de Queiroz e Silva. O corpo técnico-administrativo na autoavaliação institucional. Estudos em Avaliação Educacional, São Paulo, v. 24, n. 54, p. 220-241, jan./abr. 2013.

MASETTO, Marcos Tarciso. Avaliação Institucional - definições e posicionamentos. Estudos em Avaliação Educacional, São Paulo, p. 9-12, 1990.

MORAES, Sandro Ricardo C. Auto-Avaliação Institucional numa Escola Pública Básica da Rede Pública da Rede Estadual de São Paulo. 2008. 191 p. Dissertação (Mestrado em Educação) - Pontifícia Universidade Católica de Campinas, Campinas, 2008.

OLIVER, Ana Cristina Avaliação institucional: uso de abordagens diversificadas de pesquisa. Estudos em Avaliação Educacional, São Paulo, v. 21, n. 45, p. 13-32, jan./abr. 2010.

POLTRONIERI, Heloisa. Avaliação da aprendizagem: estudo sobre a produção científica divulgada no periódico Estudos em Avaliação Educacional (1990-2010). 2012. 165 p. Dissertação (Mestrado em Educação) - Pontifícia Universidade Católica de Campinas, Campinas, 2012.

POLTRONIERI, Heloisa; CALDERÓN, Adolfo Ignacio. Avaliação na Educação Básica: a revista Estudos em Avaliação Educacional. Estudos em Avaliação Educacional, São Paulo, v. 23, n. 53, p. 82-103, set/dez. 2012.

RIBEIRO, Elisa Antonia. Convergências e divergências das práticas de autoavaliação institucional em IES pública e privada na percepção da comunidade acadêmica. Estudos em Avaliação Educacional, São Paulo, v. 23, n. 52, p. 168-189, jan./abr. 2012.

SAMESHIMA, Dumara Coutinho Tokunaga. Avaliação Institucional: uma análise da produção do conhecimento (1990-2002). 2004. 376 p. Tese (Doutorado em Educação) Pontifícia Universidade Católica de São Paulo, São Paulo, 2004.

SAUL, Ana Maria. Avaliação da Universidade: buscando uma alternativa democrática. Estudos em Avaliação Educacional, São Paulo, n. 1, p. 17-20, 1990.

SILVA, Itamar Mendes da. A discussão sobre avaliação nas reuniões anuais da ANPED no período 2000 a 2010. Avaliação, Campinas; Sorocaba, SP, v. 18, n. 2, p. 335-350, jul. 2013.

SOUSA, Clarilza Prado de. Dimensões da Avaliação Educacional. Estudos em Avaliação Educacional, São Paulo, n. 22, p. 101-118, 2000. 
SOUSA, Clarilza Prado de. Avaliação de Instituições de Ensino Superior: discutindo a necessidade de diretrizes metodológicas e estratégias de implantação. Estudos em Avaliação Educacional, São Paulo, v. 17, n. 35, p. 103-114, set./dez. 2006.

SOUSA, Clarilza Prado de; MARCONDES, Anamérica Prado; ACOSTA, Sandra Ferreira. Auto-avaliação Institucional: uma discussão em processo. Estudos em Avaliação

Educacional, São Paulo, v. 19, n. 39, p.29-48, jan./abr. 2008.

SOUZA, Ângelo Ricardo de; DITTRICH, Douglas Danilo. Avaliação na escola, avaliação da escola: análise de uma experiência escolar. Estudos em Avaliação Educacional, São Paulo, v. 23, n. 52, p.26-46, maio/ago. 2012.

SOUZA, Maria Alba de. A Avaliação da Escola Pública de Minas Gerais. Estudos em Avaliação Educacional, São Paulo, n. 12, p. 25-32, 1995.

TEIXEIRA, Célia Regina. A concepção de Avaliação Educacional veiculada na produção acadêmica do Programa de Pós-Graduação em Educação: currículo (1975-2000). 224 p. 2006. Tese - (Doutorado em Educação). Pontifícia Universidade Católica de São Paulo, São Paulo, 2006.

ULER, Arnilde Marta. Avaliação da aprendizagem: um estudo sobre a produção acadêmica dos programas de pós-graduação em educação (PUCSP, USP, UNICAMP) (2000-

2007). 2010. 238p. Tese (Doutorado em Educação) - Pontifícia Universidade Católica de São Paulo, São Paulo, 2010.

VIANNA, Heraldo Marelim. Avaliação de Cursos pelos Alunos: considerações. Estudos em Avaliação Educacional, São Paulo, n. 29, p. 137-148, jan./jun. 2004.

Pamela Cristina Botiglieri - Universidade Federal de São Carlos São Carlos | SP | Brasil. Contato: pam_botiglieri@hotmail.com

Regilson Maciel Borges - Universidade Federal de São Carlos São Carlos | SP | Brasil. Contato: regilsonborges@gmail.com

José Carlos Rothen - Universidade Federal de São Carlos São Carlos | SP | Brasil. Contato: jcr3219@yahoo.com.br 